\title{
The Reinvention of the Health and Fitness Industry During the Coronavirus Pandemic
}

\author{
KAYLA MYERS ${ }^{1}$; MICHAEL B. BROWN ${ }^{1}$; SAMUEL C. PAYNE ${ }^{1}$; DANIEL M. ROSNEY ${ }^{1}$ \\ ${ }^{1}$ Department of Kinesiology, College of Public Health, Temple University \\ Correspondence: daniel.rosney@temple.edu (Daniel M. Rosney)
}

\begin{abstract}
The coronavirus pandemic impacted gyms and fitness centers as they were forced to close due to legislation intended to slow and stop the spread of COVID-19. This study investigated the effects of COVID-19 on gyms, trainers, coaches and individuals. We interviewed gym owners, trainers, coaches and individuals through convenience sampling. The results suggested that gyms faced substantial financial burdens resulting from COVID-19 and subsequent restrictions. As individuals became concerned about safety, virtual training became the norm. The mandated closures put financial strain on owners, causing many gyms and fitness centers to permanently close. Other gyms and fitness centers implemented creative solutions to meet the challenges of social distancing and heightened sanitation requirements, such as wiping down equipment between participant usage. As individuals became concerned about safety during COVID-19, bome fitness equipment sales skyrocketed and people rediscovered low-cost forms of exercise. When gyms began to reopen, membership rates declined, continuing to apply financial pressure on gym owners. The question remains as to whether or not society will return to traditional gym functions following the resolution of the pandemic.
\end{abstract}

\section{Background}

When the coronavirus pandemic hit the United States, 105,846 fitness centers and gyms around the country were forced to close as a result of state-specific restrictions. ${ }^{1}$ As Americans across the country were confined to their homes in March 2020, the result was an increase in sedentary behavior and potential negative health consequences. ${ }^{2}$ The pandemic ushered in the idea of the "Quarantine 15", with respect to the weight most Americans were believed to be gaining. ${ }^{3}$ This occurred as individuals gravitated toward comfort foods, often calorically dense foods high in sugar and fat. According to Nutrisystem, "sheltering in place has led to serious weight gain of up to 16 pounds for 76 percent of Americans". ${ }^{4}$ The pandemic and safety restrictions also generated feelings of depression, anxiety and generalized uncertainty for many. While these symptoms may be temporary for some, there is concern that they may endure for others.$^{5}$

In response to the pandemic, gym owners were forced to rethink their operations, maintain solvency, and develop programs to bring normalcy into their clients' lives. Fitness professionals shifted to virtual classes and offered accountability sessions incorporating human contact during a time when individuals were isolated in their homes. ${ }^{6}$ Some fitness-minded individuals refused to allow the pandemic to halt their progress. Many gyms changed their programming and began operating in new and creative ways, 
while other gyms struggled to adapt and began moving toward bankruptcy. ${ }^{7}$ Trainers maximized their free time and developed skills and techniques by taking classes and obtaining additional certifications.

As states eased their restrictions, gym owners focused on "how can they reopen and provide their customers with the health and wellness experience they're after without putting them at risk". ${ }^{8}$ Maintaining physical health and fitness is a national priority as physical inactivity and a sedentary lifestyle contribute to obesity. Individuals who are physically active often experience a protective effect against the common comorbidities of obesity, including type 2 diabetes, hypertension, and heart disease. ${ }^{9}$

To further investigate these issues, we engaged in conversations with a group of professionals who work in the fitness industry.

\section{Methods}

Twenty encounters with gym owners, coaches, trainers and individuals were carried out across eight different counties throughout Pennsylvania and New Jersey beginning in June 2020 through October 2020. All participants granted permission to be observed and interviewed in order to obtain various perspectives regarding the impact of coronavirus. The participants were selected by convenience sampling and each observation and subsequent discussion was completed in their respective gym or fitness facility. The discussions were an unstructured interview and the questions each participant was asked were based on the observations at their facility. However, each participant was specifically asked about the new COVID-19 protocols and the impact of the coronavirus pandemic.

\section{Perspective from the Gyms and Gym Owners}

The pandemic brought change which negatively impacted gyms. New requirements presented gym owners with two options: 1) choose creativity and develop virtual fitness components or 2) remain stagnant and succumb to economic pressure. Many gym owners pivoted, transitioning to online group fitness and virtual training through platforms such as Zoom and Facebook Live. Nonetheless, clients lacked access to large expensive pieces of gym equipment. To overcome this barrier, gyms offered online classes relying on body weight training and the use of home objects such as chairs and cans of food. Realizing these limitations, some owners offered their clients the opportunity to rent or purchase equipment. For example, at Reach Your Potential Training, located in Tinton Falls, NJ, clients were offered sliders and resistance bands for $\$ 15$ which solved a problem and increased the gym's income.

Gyms offered services such as online nutrition classes and accountability coaching designed to keep clients on track. Online nutrition classes enlisted nutritionists and dietitians to educate clients on proper nutrition with tailored advice. Accountability coaching enabled clients to report their nutrition intake, physical activity, and change in physical measurements to a coach who reinforced positive behavior and developed plans to overcome obstacles. These services provided education, encouraged healthy lifestyles, and met the needs of clients.

As states reopened, gym owners realized business would be different due to new safety requirements. These new procedures typically began at the door with a face mask requirement. Some gyms implemented coronavirus risk screening questions and required temperature checks. Counties and states often mandated gyms to record client check-in/check-out times to ensure adherence of capacity limits while assisting in contact tracing. This caused some gyms to maintain regular business hours, allowing members to come and go, while others offered appointment only sessions. Many gyms reopened with all in-person classes, while others utilized virtual training and outdoor classes, ensuring precautions such as social 
distancing and a "no equipment sharing" rule (Figure 1). Outdoor events require special logistics, including music. To provide upbeat and motivational music, gyms secured a DJ or utilized speakers while ensuring proper safety and sanitation. Others were even more creative. Philadelphia's Fit Academy clients exercise socially distanced at the Philadelphia Art Museum steps (Figure 2).

Figure 1. Outdoor Training, Temple University Main Campus

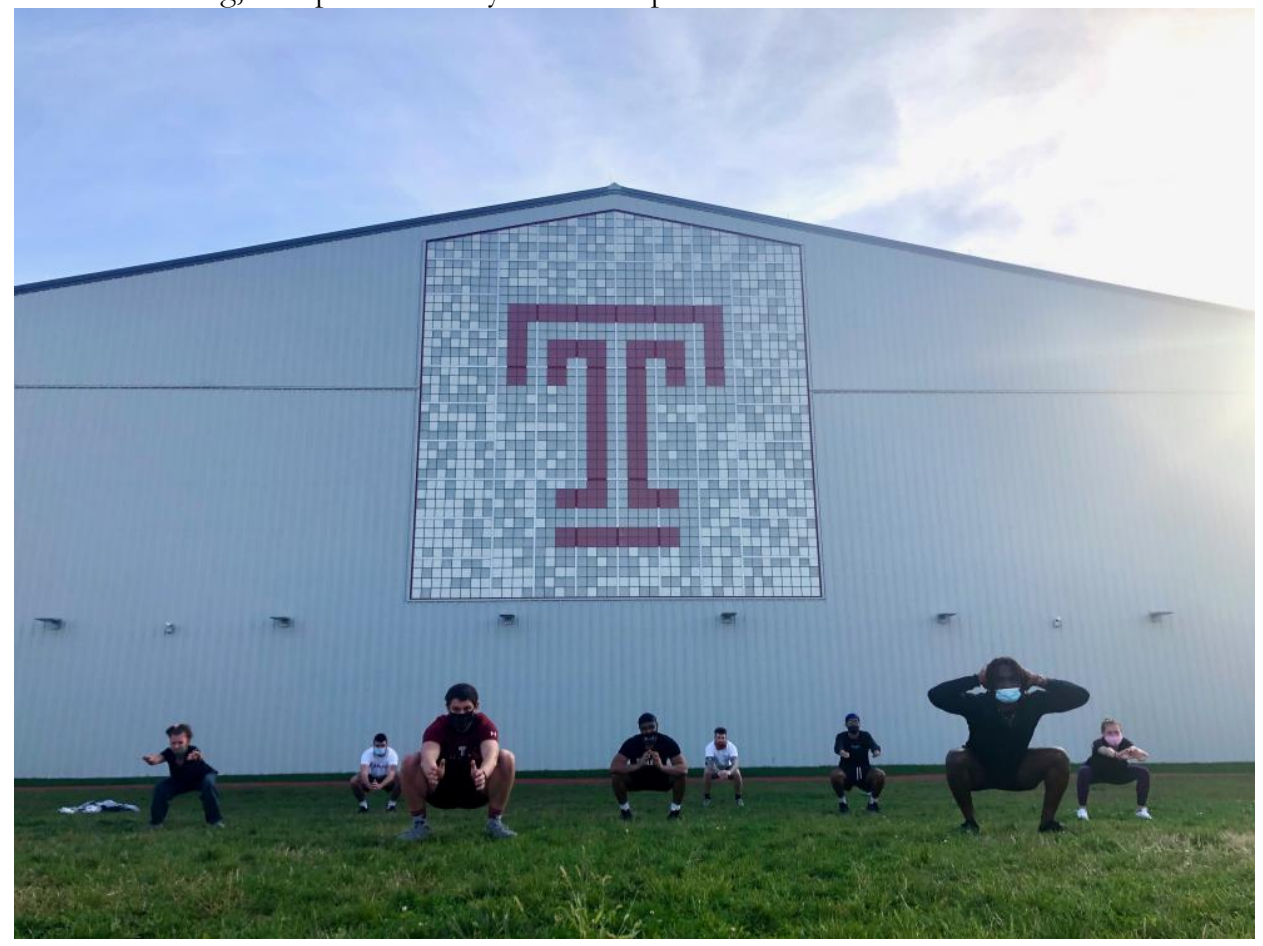

Figure 2. Fit Academy Training, Philadelphia, PA

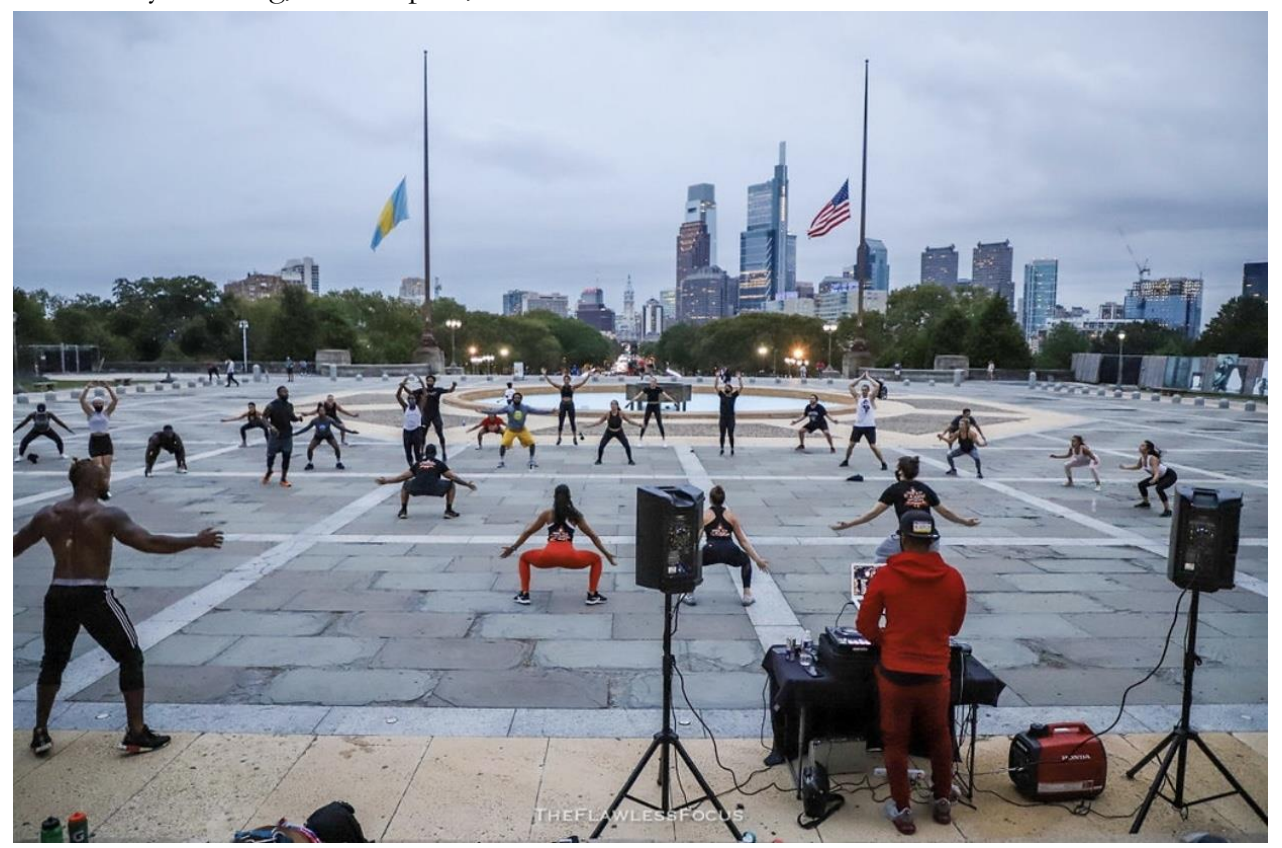


Gold's Gym, located in Bridgewater, NJ, utilized screeners, located behind Plexiglas, to ask screening questions upon arrival. The questions included: 1) Have you been in contact with anyone diagnosed with coronavirus in the last 14 days? 2) Have you experienced any symptoms in the last three days? 3) Have you traveled outside of New Jersey? If the client answered yes to this question, they were asked where they travelled and if the location was in a "red zone", they were not granted entry. Clients were required to pass a temperature check and after the screening was completed, they entered the gym and were provided a towel and spray bottle to clean equipment before and after use.

Ryan Perreault and LeeAnn Hriniak, coaches of Next Fit Clubs in Hillsborough, NJ, oversaw client temperature checks and took their own temperature in the presence of their clients to demonstrate they were "fever-free". Next Fit Clubs did not implement screening questions as this was not mandated. New Jersey required trainers, coaches, and clients to wear a mask if social distancing could not be followed, unless the client had an underlying medical issue. In July 2020, Next Fit Clubs trained clients by appointment only and did not allow walk-ins. Another notable change was decreased capacity as New Jersey mandated only a trainer and client to be within a four-wall space.

Interestingly, New Jersey Executive Order No. 157 stated indoor premises were limited to a 25\% capacity. ${ }^{10}$ This same order required gyms to operate by appointment only and to allow one client and trainer in a four-wall space during a given session. The actual language of the Executive Order led to various interpretations. For example, CJ Appenzeller, the owner of Appenzeller Training Systems in West Berlin, NJ, believed he could operate at 25\% capacity because the executive order stated ANY indoor facility could operate at $25 \%$ capacity. Each gym assessed followed the order; however, there was confusion regarding the interpretation.

Another gym located in central New Jersey opted to make minor changes. Upon entrance to the gym, there was not a Plexiglas barrier at the front desk; additionally, the receptionist was not wearing a mask. When Michael B. Brown visited the gym, his temperature was taken and verified as being within a normal range. Upon entrance to the gym the workers encouraged him to take off his mask; however, Brown chose not to follow their suggestion as masks have been shown to protect against coronavirus as stated by the CDC. ${ }^{11}$ Class sizes were approximately 15-20 athletes with three to four coaches. Athletes and coaches were unmasked and less than six feet away from each other during the indoor session (Figure 3). 
Figure 3. Athletes and Coaches Unmasked and Not Responsibly Distanced, Central NJ Gym

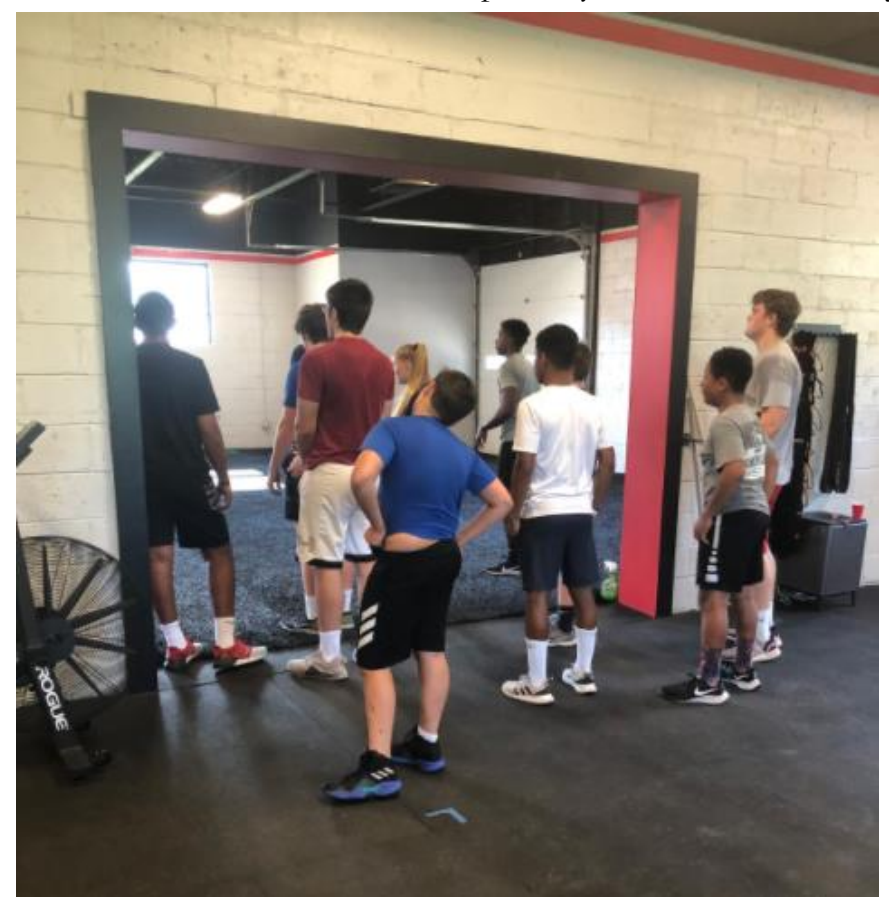

Gym sanitation was prioritized with some gyms requiring staff to clean equipment while others required members to sanitize equipment. Spray bottles, wipes and signage served as reminders to clean equipment. Owners displayed signs throughout facilities to encourage sanitation practices. Rob Zampetti, the owner of Gold's Gym in Bridgewater, NJ, installed "Air Scrubber by Aerus" units throughout the facility. This system uses light waves to send "scrubber ions" to flush out airborne viruses, germs and bacteria. Zampetti also purchased an "ElectroStatic fluid", which involved electrical ions wrapped around metal and electrical conductors, making it easier to clean equipment.

Appenzeller Training Systems transitioned to liquid chalk for athletes as a way to increase sanitation. Chalk is used to increase hand grip, especially during weightlifting. Liquid chalk is normally used in wet conditions since its performance is not affected by moisture. Samuel Payne encountered liquid chalk during a visit and when Appenzeller was asked why he switched to liquid chalk he remarked "it provides more grip on the hands and stops them from sweating". He also felt dry chalk is messy and difficult to sanitize. From Appenzeller's perspective, switching to liquid chalk limited filth and increased sanitization as the bottle can be easily wiped clean and there is less mess.

Many gyms utilized the creation of visual and/or physical barriers to separate clients. Numerous gyms used tape or stickers to designate physically distanced spacing. At Appenzeller Training Systems, athletes warmed up in specific sections designed for the facility (Figure 4). When equipment could not be moved, gyms used caution tape or signs to ensure social distancing. Taping off areas was viewed as a good solution; however, questions surrounding the efficacy of preventing the spread of COVID-19 arose. Due to these concerns, some gyms took extra precautions and built "workout pods" or creative structures enabling clients to exercise in a confined environment. While pods were more efficacious than tape, numerous gyms were unable to afford them and opted for less expensive methods of enforcing physical distancing. 
Figure 4. Designated Warm Up Areas, Appenzeller Training Systems Gym

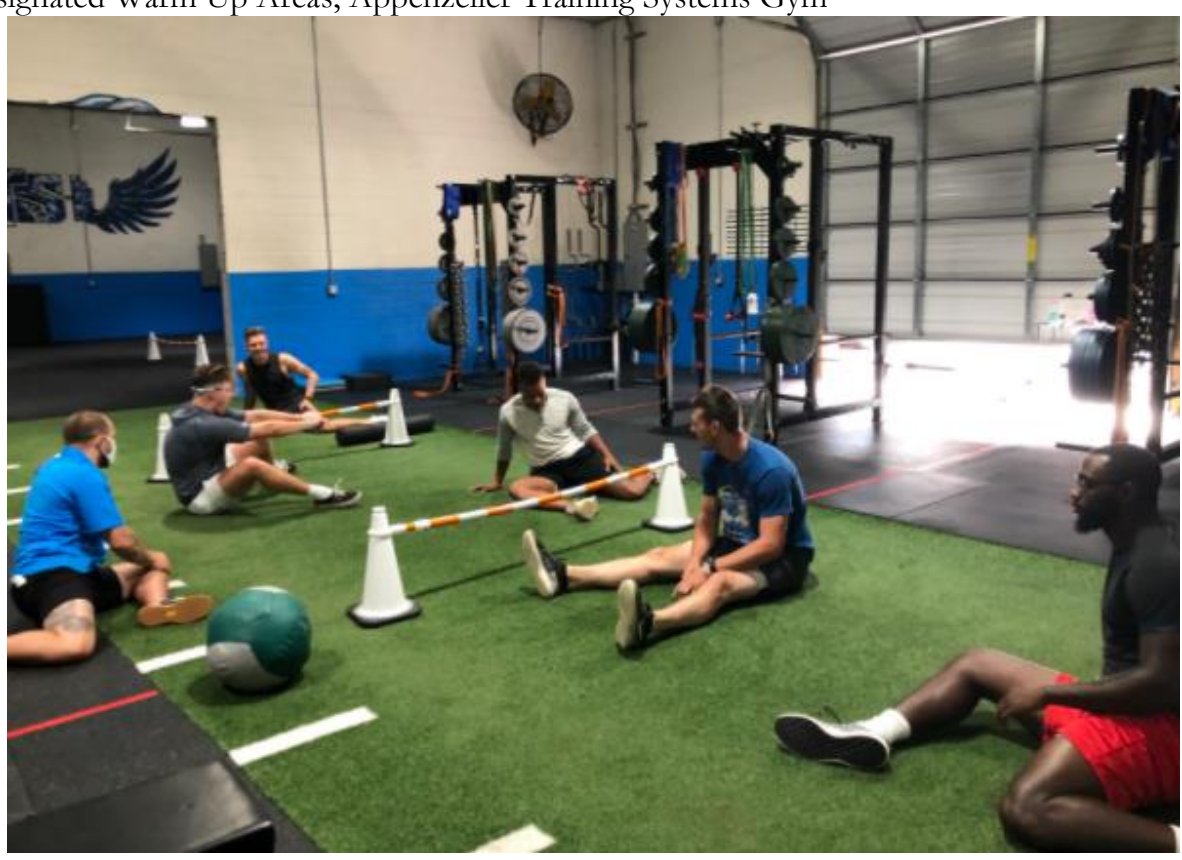

Ultimately gyms faced financial pressures as cancellations and non-renewals rose from concerns of COVID-19 exposure. Some clients discovered less expensive ways to exercise, train and condition outside of a traditional gym setting. Harrison Co. estimated that $\$ 10$ billion per year could be lost by gyms as a result of people opting for home fitness. ${ }^{12}$ Safety requirements caused owners to increase spending on sanitization while labor costs increased and capacity decreased due to state and local restrictions. The aftereffects of the pandemic placed many gyms in a precarious financial situation, forcing some to permanently close their doors or file for bankruptcy.

The shutdown taught gym owners, trainers, and coaches the importance of placing worth on their talents and skills in relation to developing programs and coaching their clients/athletes. The services they provide are not a service offered by just anyone. Trainers and coaches realized the importance of considering operational cost as well as time spent programming and maintaining proper credentials/certifications. There is no doubt this transition period challenged everyone; however, gym owners, trainers and coaches learned to adapt and found ways to ensure safety of clients and staff.

\section{Perspectives of the Gym Clients}

The closing of gyms due to COVID-19 made it difficult for J'Michael Wedderburn to participate in resistance training. However, he shifted from strength and hypertrophy training to cardio and HIIT (high intensity interval training) focused training. Wedderburn focused on cutting weight, implementing a caloric deficit and increased his running while implementing bodyweight HIIT workouts. Wedderburn did not return to the gym after they opened believing there was a component of bodyweight functional workouts that challenged and pushed his body to a new level. He explained this left him feeling less exhausted and more efficient, when utilizing his oxygen consumption at rest or when active. "A study found that five weeks of HIIT workouts performed four days per week for 20 minutes each session improved oxygen consumption by $9 \% " .{ }^{13} \mathrm{He}$ was also concerned about sanitation. His previous gym (Temple University's Aramark Student Training and Recreational Complex) closed, requiring him to locate another gym with reasonable rates should he choose to return to a gym setting. 
Seneca Williams did not alter his routine; instead, he embraced innovation striving to retain the same intensity and workload elicited at the gym. Williams purchased a pull-up bar, resistance bands and a kettlebell to ensure he was not detraining. He knew it would be challenging to achieve the same intensity with only bands and a 35-pound kettlebell. However, he realized he could achieve a higher intensity by manipulating the working sets and training for failure. "Recruiting more muscle fibers can result in more metabolic stress on the muscle, more muscle damage, and greater growth. Your body may also be accustomed to your normal training, and the method . . . can add a different stimulus to shock your muscles into growth to help you overcome plateaus. Muscular endurance may improve, as your body adapts to higher repetitions than it is used to". ${ }^{14}$ Williams was hesitant to return to the gym; when he finally returned, he was cautious in his approach. In Figure 5, Williams is seen practicing physical distancing in an almost entirely empty gym, while complying with the mask mandate.

Figure 5. Mask Wearing in a Sparsely Occupied Gym

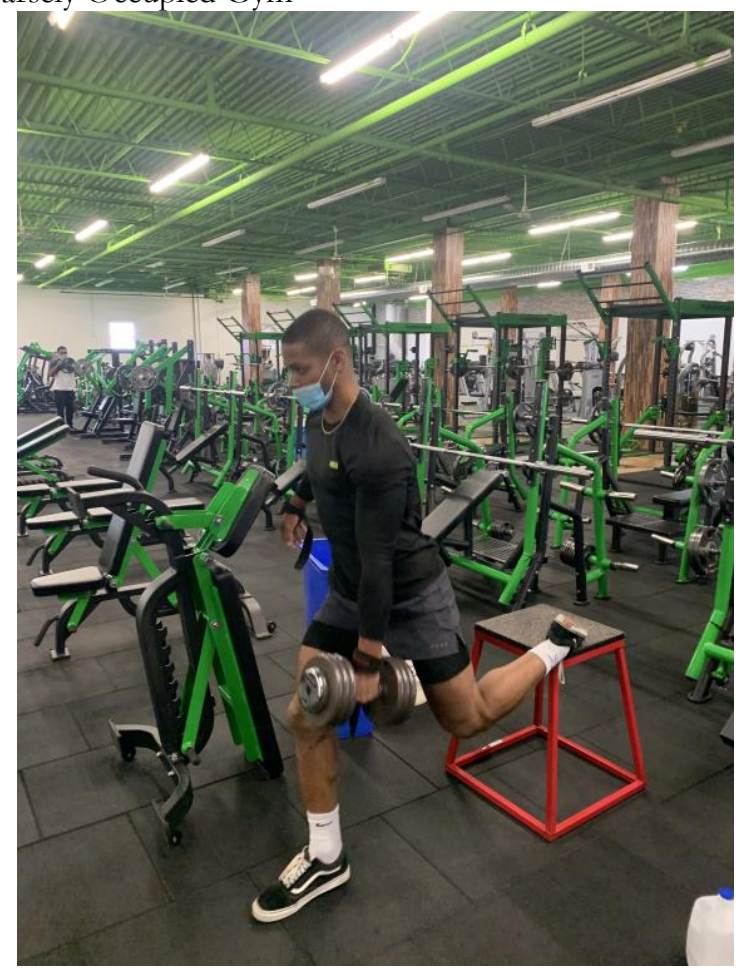

Prior to COVID-19, Samuel Payne was a frequent gym attendee, believing gyms were efficient and sanitary environments. COVID-19 caused him to realize gyms are overpopulated and frequently unsanitary. As a result, Payne has not returned to the gym and has found other ways to exercise. Payne is concerned about contracting and/or spreading COVID-19; he is not alone with this concern. A survey conducted by market-research firm OnePoll and commissioned by LIFEAID Beverage Co., found that $25 \%$ of Americans never plan to go back to the gym. ${ }^{15}$

Payne realizes few Americans attain the recommended amount of daily physical activity. Federal physical activity guidelines recommend that adults get at least 150 minutes of moderate or 75 minutes of vigorous exercise each week, in addition to_muscle-strengthening activities at least twice a week. Unfortunately, less than a quarter of Americans adults are meeting these recommendations.$^{16}$ Despite these statistics, Payne believes individuals can obtain the recommended amount of physical activity by participating in activities such as walking, hiking, running, bike riding, and gardening. 


\section{Discussion}

The pandemic has clearly and profoundly impacted the fitness industry as well as the individuals it regularly serves. Some gyms have been quite flexible in providing services throughout the year; others have already closed and may never come back. Clients have had a similar range of reaction. Some have taken advantage of the creativity seen by some gyms. Other clients remain concerned about exercising in gyms and have found other ways to maintain their fitness and health.

The pandemic also has contributed to the increased popularity of state-of-the-art equipment and other less expensive fitness alternatives. For instance, The Mirror, a picture interactive screen the size and shape of a mirror, streams over 70 different live and on-demand fitness classes with varying intensities at a cost of $\$ 1,500$ plus a monthly subscription. ${ }^{17}$ The Tonal is another piece of equipment that adds a resistance training element which gradually increases weight with progression. The Tonal has a trainer, ensuring proper form and technique while offering motivation at a cost of $\$ 3,000-\$ 3,500$, depending on accessories packages. ${ }^{18}$ For those who enjoy cycling, the Peloton allows individuals to take on-demand and livestream classes with other Peloton members. This option allows for a motivational cardio experience for an initial investment of $\$ 2,245-\$ 2,495$ plus a monthly membership. ${ }^{19}$

Those looking for affordable options utilized free and low-cost fitness apps such as FitOn, which "offers a library of exercises, including HIIT workouts, dance classes, barre exercises, targeted toning workouts and kickboxing classes". ${ }^{20}$ Others individuals turned to wearable technology, such as Fitbit, Amazon's Halo band, and other popular activity trackers. ${ }^{21}$ This technology keeps track of activity levels and typically increases activity. Others began walking, running or cycling, which are no cost options. Ultimately, "the pandemic has changed the way we engage with activity and it will continue to do so as we begin the gradual journey towards a new normal as more sport and leisure facilities open up". 22

The pandemic brought many challenges to the fitness industry; however, instead of being discouraged, many individuals rose to the occasion which led to opportunities. Due to the high-touch nature of the fitness industry, gyms were the first to close, resulting in financial strain, including bankruptcy. ${ }^{23}$ As individuals began working out at home, the lack of exercise equipment was apparent. To complicate matters, equipment quickly became in short supply. As workouts transitioned to a virtual setting, interpersonal connections were difficult to recreate and ensuring clients maintained proper form and were safe in their homes became areas of concern.

Despite these challenges, some individuals began working out more frequently. ${ }^{24}$ This quickly became an area of opportunity as fitness facilities were able to increase the quantity and quality of virtual classes. Many virtual classes allowed individuals the ability to stream content when convenient. Since these workouts were able to be done at home, individuals spent less time overall working out when factoring in the reduced need for transportation. As individuals embraced technology, many began downloading fitness apps at an increased rate. ${ }^{25}$ Individuals turned to the internet for additional fitness options and discovered equipment such as The Mirror, The Tonal, and Peloton. The heightened demand for equipment and technology, due to the coronavirus pandemic, resulted in the fitness industry rapidly expanding in terms of equipment and technology.

The present study had a number of limitations. The main limitation was the use of a small, convenience sample. A narrow geographical footprint of eight counties across two northeastern states may not be representative of the national impact and response to the coronavirus. Collection of objective data of number of clients in the gyms over time, or monitoring of the use of fitness equipment, either in the 
gyms or at home, would provide more informative data about changes in fitness behavior in response to the pandemic.

\section{Conclusion}

As COVID-19 rapidly spread across the United States, Americans discovered a "new normal". Businesses shuttered and lives were altered. The fitness industry was heavily impacted as revenue was immediately cut off due to mandates enacted in an effort to stop the spread of the virus. Gym owners, trainers, and coaches alike were determined in their efforts to continue their mission of helping individuals achieve and maintain a healthy lifestyle. Consequently, the traditional approach of fitness modeled around a gym was reassessed. An evaluation of gym membership prior to the pandemic and the subsequent COVID19 regulations led fitness professionals to develop virtual programming and additional services, while individuals began to realize their own ability to incorporate physical activity into their daily lives utilizing at-home equipment. This desire for in-home fitness devices led gym owners to rent out or offer options to purchase equipment. As days of home confinement passed, individuals began to invest in exercise gear previously not considered due to cost.

As the number of cases of COVID-19 began to decrease in the summer and fall of 2020 and states opened up, gyms were faced with increased requirements designed to ensure safety of staff and clients. These safety requirements resulted in increased costs at a time when capacity was limited. Despite the challenges posed by the coronavirus pandemic, gyms, trainers, and individuals actively sought out creative solutions to achieve and maintain a healthy lifestyle. The actions of fitness professionals and individuals demonstrate the resiliency and tenacity of the human spirit to adapt to challenges.

Gyms, trainers, coaches, and individuals must remain creative and flexible as COVID-19 is a fluid situation. On Friday November 20, 2020 new restrictions were implemented in Pennsylvania, requiring the wearing of masks, as well as the requirement for a negative test result upon entry of out-of-state travelers. Furthermore, the city of Philadelphia closed indoor dining, museums, libraries and gyms in an attempt to limit gatherings due to cases on the rise. Other states, such as New Jersey and Delaware, mandated limits on gatherings effective the following Monday, November 23rd, 2020.26 As COVID-19 cases continued to rise, Governor Tom Wolf and Secretary Levine enacted new mandates including the immediate suspension of school extracurricular activities and sports, suspension of indoor dining, and suspension of recreation, which includes the closure of gyms through January 4, 2021.27 The implementation of new restrictions will continue to impact gyms as many states are requiring them to close their doors once again. As a result, many trainers and coaches fear a lack of job security as state mandates prevent individuals from training indoors. Similar to the onset of the pandemic, we must once again endeavor to work together for creative solutions to reinvent the health and fitness industry.

\section{Disclosures and Conflicts of Interest}

The authors disclose no conflicts of interest.

\section{References}

1. Industry Market Research, Reports, and Statistics. IBISWorld.

https://www.ibisworld.com/industry-statistics/number-of-businesses/gym-health-fitness-clubs-unitedstates/. Accessed October 15, 2020. 
2. Jakobsson J, Malm C, Furberg M, Ekelund U, Svensson M. Physical Activity During the Coronavirus (COVID-19) Pandemic: Prevention of a Decline in Metabolic and Immunological Functions. Frontiers in Sports and Active Living. 2020;2. doi:10.3389/fspor.2020.00057

3. Robinson B. What Is "Quarantine 15"? Psychology Today. https://www.psychologytoday.com/us/blog/the-right-mindset/202003/what-is-quarantine- 15. Published March 30, 2020. Accessed October 15, 2020.

4. Moore C. Coronavirus prompts double-digit weight gain for Americans under lockdown. Fox Business. https://www.foxbusiness.com/lifestyle/coronavirus-weight-gain-76-americans-nutrisystem. Published July 8, 2020. Accessed November 19, 2020.

5. Torales J, O'Higgins M, Castaldelli-Maia JM, Ventriglio A. The outbreak of COVID-19 coronavirus and its impact on global mental health. International Journal of Social Psychiatry. 2020;66(4):317-320. doi:10.1177/0020764020915212

6. Sleem S. Fitness instructors making the switch to virtual classes.

https://www.newschannel5.com/news/ fitness-instructors-making-the-switch-to-virtual-classes. Published March 23, 2020. Accessed December 11, 2020.

7. Petrzela NM. How Long Can Gyms Survive? Medium. https://marker.medium.com/howlong-can-gyms-survive-2bf888c1338f. Published October 29, 2020. Accessed December 11, 2020.

8. Litwin D. Gym Owners Share Strategies for Reopening in the Wake of COVID-19

MarketScale. MarketScale B2B Industry News. https://marketscale.com/industries/sports-andentertainment/gym-owners-share-strategies-for-reopening-in-the-wake-of-covid-19/. Published August 7, 2020. Accessed December 11, 2020.

9. Blair SN, Brodney S. Effects of physical inactivity and obesity on morbidity and mortality:

current evidence and research issues. Med Sci Sports Exerc. 1999;31(11 Suppl):S646-S662. doi:10.1097/00005768-199911001-00025

10. Abhishek. The Official Web Site for The State of New Jersey.

https://nj.gov/infobank/eo/056murphy/approved/eo_archive.html. Published June 26, 2020. Accessed October 14, 2020.

11. CDC. Considerations for Events and Gatherings. Centers for Disease Control and

Prevention. https://www.cdc.gov/coronavirus/2019-ncov/community/large-events/considerationsfor-events-gatherings.html. Published July 7, 2020. Accessed October 14, 2020.

12. Myers R. Consumer Fitness Survey Finds Post COVID-19, Billions in Spend Will Be Lost or Reallocated in Massive Industry Transformation. https://www.businesswire.com/news/home/20200526005202/en/Consumer-Fitness-Survey-

Finds-Post-COVID-19-Billions-in-Spend-Will-Be-Lost-or-Reallocated-in-Massive-Industry-

Transformation. Published May 26, 2020. Accessed November 19, 2020.

13. Tinsley G. 7 Benefits of High-Intensity Interval Training (HIIT).

https://www.healthline.com/nutrition/benefits-of-hiit. Published 2017. Accessed October 14, 2020.

14. Reid F. Training To Failure: Benefits And Methods. MYPROTEIN.

https://www.myprotein.com/thezone/training/training-to-failure-benefits-and-methods/. Published November 11, 2019. Accessed October 14, 2020.

15. Ducharme J. COVID-19 Is Bad for Gyms. It Could Be Great for Exercise. Time.

https://time.com/5867166/covid-19-gyms-exercise/. Published July 15, 2020. Accessed October 14, 2020.

16. Ducharme J. Only 23\% of Americans Get Enough Exercise, a CDC Report Says. Time.

https://time.com/5324940/americans-exercise-physical-activity-guidelines/. Published June 28, 2018. Accessed October 14, 2020.

17. Product. https://www.mirror.co/shop/mirror. Accessed October 16, 2020.

18. Tonal. Buy. Tonal. https://www.tonal.com/product/tonal/. Accessed December 14, 2020.

19. Peloton. Exercise Bike With Indoor Cycling Classes Streamed Live \&amp; On-Demand.

Peloton ${ }^{\circledR}$. https://www.onepeloton.com/. Accessed December 14, 2020 
20. Wilson J. The Best Ways To Exercise At Home During Coronavirus. HuffPost. https://www.huffpost.com/entry/exercise-at-home-coronavirus_1_5e98bd74c5b6ead14009f2bb.

Published April 20, 2020. Accessed October 15, 2020.

21. Heater B. Low-cost fitness bands see a resurgence in interest amid the pandemic.

TechCrunch. https://techcrunch.com/2020/09/04/low-cost-fitness-bands-see-a-resurgence-ininterest-amid-the-pandemic/. Published September 4, 2020. Accessed October 15, 2020.

22. O'Keefe L. Surge in appreciation of exercise and activity during lockdown. Sport

England. https://www.sportengland.org/news/surge-appreciation-exercise-and-activity-duringlockdown. Accessed October 15, 2020.

23. Omnify. Impact of Covid-19 on the Fitness Industry. RSS.

https://www.getomnify.com/blog/impact-of-covid-19-on-the-fitness-industry. Accessed December 14, 2020.

24. Cording J. How COVID-19 Is Transforming The Fitness Industry. Forbes.

https://www.forbes.com/sites/jesscording/2020/07/13/covid-19-transforming-fitnessindustry/amp/. Published July 13, 2020. Accessed December 14, 2020.

25. Williams R. Fitness apps see 67\% jump in installs during pandemic. Marketing Dive. https://www.marketingdive.com/news/fitness-apps-see-67-jump-in-installs-duringpandemic/583914/. Published August 21, 2020. Accessed December 14, 2020.

26. Staff CBS. When New COVID-19 Restrictions Go Into Effect In Pennsylvania, New Jersey

\& Delaware. https://philadelphia.cbslocal.com/2020/11/20/when-new-covid-19-restrictions-go-intoeffect-in-pennsylvania-new-jersey-delaware/. Published November 20, 2020. Accessed November 20, 2020.

27. Yilek C. Pennsylvania Governor Tom Wolf announces new COVID-19 restrictions. CBS

News. $\quad$ https://www.cbsnews.com/news/pennsylvania-new-covid-19-restrictions-2020-12-10/. Published December 10, 2020. Accessed December 14, 2020.

\section{Statement of Contributions}

All authors contributed to the writing and editing of this paper. Kayla Myers and Michael B. Brown captured the images used throughout the document. Michael B. Brown and Samuel Payne contributed to the completion of the research and interviews. 